\title{
Self-reported sexually transmitted infection testing behaviour amongst incarcerated young male offenders: findings from a qualitative study
}

\author{
Katie Buston, Daniel Wight
}

\begin{abstract}
Introduction Sexually transmitted infections (STIs) are a major public health problem in the UK. Here we describe young men's self-reported STI testing behaviour, and explore why testing is and is not sought in two locales: the community and the Young Offender Institute (YOI).
\end{abstract}

Methods In-depth interviews were conducted with 40 men, aged 16-20 years, whilst incarcerated in a Scottish YOI. The participants were purposively sampled using answers from a questionnaire administered to 67 inmates.

Results The majority $(n=24)$ of those interviewed reported having undergone STI testing: eight in the community, 12 within the YOI, and four in both the community and the YOI. The extent to which they were worried about STIs and perceived themselves 'at risk' was important in understanding openness to testing. The convenience of testing within the YOI boosted the numbers seeking testing once incarcerated. Not getting tested in the YOI was due to not realising that it was available or not getting around to it rather than objecting to, or being embarrassed about, testing.

Discussion Increasing awareness of the availability of STI testing within YOls would be likely to result in higher uptake. An opt-out YOI STI screening programme would probably result in very high testing rates. Accessibility and convenience are key elements of testing procedures for this group, in both the $\mathrm{YOI}$ and community settings.

Keywords chlamydia, prison, sexually transmitted infections, STI testing, young offenders

J Fam Plann Reprod Health Care 2010; 36(1): 7-11

(Accepted 11 August 2009)

\section{Introduction}

Sexually transmitted infections (STIs) are a major public health problem in the UK. STI rates have risen amongst young people (aged 16-24 years) over the last decade; and although young people represent $12 \%$ of the population, they account for nearly half of STI diagnoses within genitourinary medicine (GUM) clinics $^{1}$ where STI testing is available free of charge and in confidence. Those individuals who are infected often have few or no symptoms and, if left untreated, STIs can have long-term effects on health, particularly for the female partner. ${ }^{2}$ There has been growing discourse advocating the involvement of men, particularly young men, in screening, ${ }^{3-5}$ and around the utility of non-medical settings as key access points for reaching these men. 6

Most prisoners come from the poorest and most socially excluded sections of society. 7,8 High rates of sexual partner change and acquisition of STIs amongst young male prisoners, prior to entering Young Offender Institutes (YOIs), linked to drug and alcohol use, have become a concern. ${ }^{8-10}$ The National Chlamydia Screening Programme in England, which screens men and women aged under 25 years, has found that the highest positivity of chlamydia is within prison, at 14\%. ${ }^{11}$ In the USA, in 2007 at least 37 states had STI screening programmes in place in correctional facilities; 12 positivity for chlamydia and gonorrhoea in these venues are consistently among the highest observed. ${ }^{13}$

In this article we explore the accounts of incarcerated male young offenders to better understand what motivates them to seek testing for STIs: in the community and/or in the YOI. We also explore why others have not been tested.

MRC Social and Public Health Sciences Unit, Glasgow, UK Katie Buston, BA, PhD, Senior Investigator Scientist

Daniel Wight, MA, PhD, Programme Leader

Correspondence to: Dr Katie Buston, MRC Social and Public Health Sciences Unit, 4 Lilybank Gardens, Glasgow G12 8RZ, UK. E-mail: Katie@sphsu.mrc.ac.uk

\section{Key message points \\ - The introduction of a Young Offender Institute-based opt-out sexually transmitted infection-screening programme should be considered. \\ - Targeting male young offenders whilst they are incarcerated may provide a rare window of opportunity to intervene in the lives of these high-risk young men. \\ - Accessibility and convenience are important when designing testing initiatives for this group.}

We discuss the implications for the development of withinprison testing initiatives, as well as for increasing uptake of STI testing amongst young men, in particular hard-to-reach and socially excluded young men, within the community.

\section{Methods}

These findings are from a primarily qualitative study of male young offenders' attitudes and experiences in relation to sex and relationships. ${ }^{14}$ Self-completed questionnaires were administered to 67 inmates, aged 16-21 years, at a Scottish YOI. Time constraints, particularly as one-to-one administration of the questionnaire to the men was thought desirable, led us to limit the study to a sub-sample of inmates. For logistical reasons those approached to participate were all new admissions, over a period of several months, as well as those in contact with a prison officer with a youth support remit. All but one of the men approached agreed to participate. There is no reason to suppose that those surveyed are not representative of the population of this particular YOI with regard to their offending behaviour, their sexual behaviour and other characteristics. One of the authors (KB) conducted indepth interviews with 40 of these men, the maximum number it was possible to interview, and analyse transcripts for, in the time available to complete the study. All of those approached to be interviewed agreed.

The interview and questionnaire covered topics such as sex education and pregnancy, as well as STIs and testing for STIs. Paramount when designing the questionnaire and interview schedule were concerns about reading and 
Table 1 Characteristics of the interviewees $(n=40)$

\begin{tabular}{|c|c|}
\hline Characteristic & Interviewees $(n)$ \\
\hline \multicolumn{2}{|l|}{ Sex education } \\
\hline $\begin{array}{l}\text { Good or excellent sex education } \\
\text { from one or more sources }\end{array}$ & 25 \\
\hline \multicolumn{2}{|l|}{ Girlfriends } \\
\hline Girlfriend at present & 21 \\
\hline Girlfriend in past & 16 \\
\hline Never had girlfriend & 3 \\
\hline \multicolumn{2}{|l|}{ Sexual partners $(n)$} \\
\hline $2-5$ & 5 \\
\hline $6-10$ & 12 \\
\hline$>10$ & 23 \\
\hline \multicolumn{2}{|l|}{ Contraceptive use } \\
\hline Every time & 1 \\
\hline Most times & 13 \\
\hline About half the time & 6 \\
\hline Not very often & 9 \\
\hline Never & 8 \\
\hline Don't know/can't remember & 3 \\
\hline \multicolumn{2}{|l|}{ Caused a pregnancy } \\
\hline No & 28 \\
\hline Don't know, maybe & 3 \\
\hline Once & 5 \\
\hline More than once & 4 \\
\hline \multicolumn{2}{|l|}{ Testing for STls } \\
\hline Not tested & 16 \\
\hline Tested & 24 \\
\hline Tested in community only & 8 \\
\hline Tested within YOI only & 12 \\
\hline Tested in community and YOI & 4 \\
\hline Tested once & 16 \\
\hline Tested twice & 3 \\
\hline Tested three or more times & 5 \\
\hline Positive diagnosis & 5 \\
\hline \multicolumn{2}{|l|}{ Age (years) } \\
\hline 16 & 1 \\
\hline 17 & 4 \\
\hline 18 & 17 \\
\hline 19 & 13 \\
\hline 20 & 5 \\
\hline \multicolumn{2}{|l|}{ Residential care } \\
\hline Yes & 7 \\
\hline No & 33 \\
\hline \multicolumn{2}{|l|}{ Religion grown-up with } \\
\hline None & 22 \\
\hline Christian: Catholic & 10 \\
\hline Christian: Protestant & 7 \\
\hline Muslim & 1 \\
\hline \multicolumn{2}{|l|}{ Qualifications } \\
\hline None & 14 \\
\hline Standard grades or equivalent onlya & 20 \\
\hline Other & 6 \\
\hline
\end{tabular}

aStandard grades are the examinations at the end of statutory education.

STI, sexually transmitted infection; YOI, Young Offender Institute.

comprehension levels amongst the sample. Language used in questioning was simple and it was stressed to the men when the questionnaire was being administered and during the interview - that they could ask for further clarification if they did not understand anything. The questionnaire was piloted with five inmates; changes were made following this pilot. Between interviews, tapes of earlier interviews were listened to, and transcripts studied. The researcher therefore learned as she went along what forms of questioning tended to work best, and what areas appeared particularly pertinent and should be covered in a more indepth way in future interviews. This process is referred to as 'iterative' in qualitative methodology. 15

Scotland's two YOIs house men aged 16-21 years. The YOI in which this study was conducted houses prisoners transferred from Scotland's other YOI after being classified as 'low risk' in terms of harming themselves or others. The interview sample was selected purposively ${ }^{15}$ from the questionnaire sample to represent a broad range of sexual, reproductive and STI histories. The interview sample is fairly representative of the questionnaire sample, slightly over-representing those who assess their school sex education positively, and slightly under-representing those who never or rarely use contraception. Table 1 shows the characteristics of those interviewed.

All the interviews were conducted in private in a room within the YOI. The interviews were audio-recorded and averaged 1 hour in length. They were transcribed verbatim and the young men were given pseudonyms. Framework Analysis was used to analyse the data. ${ }^{16}$ The Framework method is designed for qualitative data, enabling iterative systematic analysis that allows for new concepts emerging throughout the analytical process. First, descriptive analysis was undertaken focusing on classifying the data and making sense of what was happening in relation to particular areas within the dataset. This was used as a base in order to move on to higher explanatory accounts that identified patterns and linkages in the data and developed explanations.

\section{Ethical approval}

Ethical approval was granted by the University of Glasgow's Faculty of Law, Business and Social Science Ethical Committee, and from the Scottish Prison Service (SPS) Research Access and Ethics Committee.

\section{Results}

Some 24 of the 40 men interviewed reported having had one or more STI tests. Eight said they had been tested outside of the YOI only, 12 reported being tested inside the YOI only, and four reported having been tested both in the community and within the YOI. Eight of the men reported repeat testing; five of these reported undergoing frequent (three times or more) testing. Three reported a positive chlamydia diagnosis, two of whom also reported having had genital warts. Two reported having been treated for thrush. Whether or not they had actually been tested, 36 of the men reported being open to the idea of testing, with only four saying they would not be interested in having an STI test.

Awareness of STIs was high: all the men were aware that infections could be caught by having unprotected sex, and most were able to name at least one such infection. Chlamydia was the infection most often mentioned (by 25 of the men). The men tended to know that chlamydia was often non-symptomatic. Nearly all the men acknowledged that they had been at risk of contracting an STI; all reported having had sexual intercourse with two or more women, and only one had used a condom on every occasion. None of the men reported sexual intercourse with another man. Factors explaining whether individual men moved beyond openness to the idea of testing to actually seeking testing are discussed below.

\section{Salience and concern about STIs}

The salience of STIs to the men varied. Amongst the frequent testers, however, the link between concern about STIs and testing was strong, with all five of these men expressing particular revulsion about having an STI, describing STIs as "unappealing", "scary", "minging" and/or "dirty". As Patrick said: "It'd make me feel sick.... Fuck that, that genital herpes or whatever it's called. I've seen pictures of that. That doesn't look nice mate.... I love my cock".

\section{Risk behaviour}

All five of the frequent testers reported having had more than 30 sexual partners, a large proportion of whom were 
one-off casual partners, and condom use amongst this group was sporadic at best. Conversely, three of the four men who said they would definitely not be interested in having an STI test were the only ones who reported three or fewer sexual partners. They also reported relatively high condom use. There were, however, men in the sample who reported a high number of sexual partners and rarely using condoms, who had not sought testing.

\section{Critical incidents in motivating men to seek testing in the community}

A number of critical incidents were cited by the men as motivating them to seek testing for the first time within the community. The majority of these concerned either them experiencing worrying symptoms $(n=5)$ and/or having unprotected sex with particular women whom they deemed relatively likely to have an STI. Indeed, the term 'dirties' was used by many of the men to refer to women who they perceived to be infected and, as such, unclean. Six of the men disclosed having had intercourse with such women, and several more did not use the term but expressed similar sentiments about particular women. Callum said: "I've only been with a couple of dirty lassies but that's why I had myself checked".

Nearly all the men had sought a test of their own initiative, but three were 'pushed' into being tested by others: their mother, girlfriend or a friend.

\section{Requesting a test within the YOI}

The men were told during their induction that they could request an STI test at any time by completing a form and returning it to the Health Centre. They may have been reminded of this subsequently by Health Centre staff during consultations, at an occasional Health Day where stalls with information appeared, or at the sexual health day run by a prison officer and Health Centre staff that some of the men interviewed attended (see below). Twelve of the men, however, said that they were not aware that they could request a test at any time.

Within the YOI, the men presented their take up of testing as being because it was readily available, convenient, straightforward and the time required was not at the cost of more interesting pursuits, as in the community. David, for example, reported requesting a test: "Just for something to dae ... any opportunity to get out of your peter [cell] innit?"

A few of the men said they "may as well" take a test, "just in case" they had an infection. For a few other men, taking up STI testing was part of their approach to take up everything that was offered because they would not necessarily have the same opportunities on the outside, because they felt it looked good on their records, and/or because anything to break the monotony of the prison routine was to be welcomed.

The sexual health day run in the YOI was attended by 13 of the interviewed men. Most had already undergone an STI test. Three additional men, however, reported requesting an STI test immediately after, and as a result of, attending the course. As well as raising their consciousness about the unpleasantness of having an STI, it reminded them that testing was available within the YOI. Sean explained: "We seen all the diseases and that. It was just disgusting, eh, and I thought 'I'd better check myself out' .... It was about a week after, I asked the nurse and she put us on [the list for a test]."

Kieran reported that when one of the course facilitators - a prison officer - directly asked the men attending the course on that particular day if any of them wanted an STI test "most of us just took it".

\section{Frequent testers}

Amongst those who had been tested three or more times there was a sense that undergoing regular testing was part of their sexual health maintenance routine. For all of them when on the outside, sex was very important, and "pulling birds" (ie, being successful in ending the night having intercourse with a woman) was a feature of their lives on a weekly, or more regular, basis and central to their selfconcept of masculinity. Patrick, for example, stated that to "get a bird" it was necessary to "look after yourself" by ensuring good sexual health: "I get a blend, a two on top and a nought on the sides, the fronts rounded off and that. I go on the sun beds for 12 minutes every day. Me laces are never out of place and that, know what I mean? I always look the part and that. Nice little Rolex on. You've gotta [get your sexual health checked] .... I don't look up to the people who, you know, the way some lads look up to people who are like 'oh, he's hard him, he's got guns', I look up to people who can pull a bird".

\section{Men who have not been tested}

Sixteen of the men reported not having had an STI test. In the community this tended to be because they felt there was no urgent need, they had not spent much time considering it or, for a small number, they had considered it but the sexual health clinic was too far away to fit a visit into their work schedule. Within the YOI testing had not been sought by the men either because they had not realised testing was available, or they "hadn't got round to it". Most "wouldnae mind having one [a test]". Only four said that they would not want to be tested. Three felt they had no need: they were the only men in the sample to report three or fewer partners $(n=3)$ and also reported a high level of condom use: "nae point, I'm doing all right"”. One respondent admitted he would be too embarrassed to be tested.

\section{Diagnosis}

Of the five men who had been diagnosed with chlamydia, genital warts and/or thrush, two were frequent testers. One reported seeking testing in the community once every 3 months because the first time he sought testing - after listening to a friend talk about a chlamydia diagnosis and recognising his friend's symptoms as his own - he had been diagnosed with chlamydia. Whilst very keen not to contract another STI, he was very matter-of-fact about his diagnosis, saying chlamydia was "wan of the easiest things to catch", and insisting he would never feel embarrassment at being tested or diagnosed as doctors "deal wae that every day". His masculinity was not threatened by frequent testing, but by the possibility of being "riddled" with an STI. Positive chlamydia diagnoses were also underplayed by the other two men who had received such diagnoses, neither of whom had plans to be tested again. One felt having chlamydia was "nothing major" and the other pointed out that it was so easy to get rid of that if it happened again it was simply a case of taking some tablets.

\section{Discussion}

The study shares the limitation of many qualitative studies in that there was a trade-off between the number of men interviewed and the in-depth nature of the interviews. Interviewing the men in greater depth would have facilitated further exploration of the issues discussed here. The study was designed, however, to collect data on a range of issues pertinent to the men's sexual health. This, combined with time constraints encountered because of the routines of prison life, meant that time available to talk to the men was limited. 
Incarcerated 16-21-year-old males only constitute 1\% of Scotland's males in this age group, ${ }^{17,18}$ limiting the generalisability of these results. It is worth highlighting, however, that many of these men are unlikely to have agreed to such research outside prison, even if they could be reached. As such, this has been a valuable opportunity to talk to socially excluded young men about their STI testing behaviour and to explore the utility of the YOI as a testing location.

The difficulties of collecting valid and reliable information on sexual behaviour have long been recognised. ${ }^{19}$ The in-depth interview is widely accepted as one of the best ways to elicit people's own understandings, with the researcher able to demonstrate interest and empathy with the respondent in order to maximise his trust and full collaboration. However, it may also mean that the respondent picks up on clues as to what the interviewer would like to hear, shaping his account accordingly. ${ }^{20,21}$ The findings reported here should be considered in this light; the men may have wanted to present themselves as behaving in a sexually responsible manner, for example, in order to comply with what they thought I - a 'respectable' woman in her late-thirties working for a government health organisation - might want to hear. It is acknowledged that the study would have been strengthened if YOI and community clinic records had been accessed to verify the men's reports of their testing behaviour, but this was beyond the scope of the original research design for which ethics approval was sought.

The unanimous agreement amongst those approached to take part in the in-depth interviews raises the issue of how 'real' consent was. It should be emphasised that no one was coerced into taking part and, by and large, the men appeared pleased to have the opportunity to talk about their lives, in confidence, to someone who was not a member of the prison staff nor affiliated with the prison system.

If screening is to be a priority [rather than, or in addition to, health promotion initiatives that focus on STI prevention through safe(r) sex], findings here suggest that the YOI could be an important locale in which to introduce a screening programme. Although, at present, within Scotland's YOIs STI testing is readily available, it is on an opt-in basis, and not all inmates are aware that they can request a test at any time. Data collected here suggest there are few objections to being tested. Not having got around to seeking a test rather than reluctance explains why some who are aware of the test's availability but have not been tested. An opt-out testing programme may, therefore, be feasible. If this is not thought to be desirable, for cost or other reasons, more, and ongoing, publicity about the availability of testing is likely to increase take-up further. A study undertaken, several years ago, in a Scottish prison housing male inmates several years ago established that a proactive chlamydia testing system within the jail was acceptable. ${ }^{22}$ Some work with young women suggested that if they are directly offered a test they are very likely to accept. ${ }^{23}$ Young men appeared even more willing than young women to accept the offer of a chlamydia test in two recently conducted studies. ${ }^{24,25}$ Convenience was particularly important to those questioned. ${ }^{24}$

Targeting male young offenders whilst they are incarcerated may provide a rare opportunity to intervene in the lives of vulnerable young men. Thirty of the 40 men interviewed here were not frequent testers, yet reported having had more than five sexual partners and instances of unprotected sex. It is likely that a screening programme, preferably opt-out but if not with more proactive recruitment than at present, would enable the diagnosis and treatment of STIs amongst this group, as well as serving as an opportunity for sexual health promotion and, perhaps, contact tracing. This should reduce the prevalence of STIs in the community in the medium and longer term as many of those incarcerated in YOIs will be released back into society in a matter of months rather than years. Their return to the community free of STIs will have benefits for future partners, and if they exhibit changed sexual and/or STI testing behaviour also as a result of prison interventions then this will have implications for STI acquisition in the period following their immediate release. Work is needed in other institutions/locales such as oil rigs, the army, and adult male and female prisons in order to explore the feasibility of introducing such a programme there.

\section{Acknowledgements}

The authors would like to thank the 67 young men who took part in the study, and the Scottish Prison Service who granted them access to the men.

\section{Statements on funding and competing interests}

Funding This study was funded by the UK Medical Research Council as part of the Sexual and Reproductive Health Programme (WBS U.1300.00.005) at the Social and Public Health Sciences Unit.

Competing interests None identified.

\section{References}

1 Health Protection Agency Centre for Infections. Sexually Transmitted Infections and Young People in the United Kingdom: 2008 Report. London, UK: Health Protection Agency Centre for Infections, 2008.

2 Department of Health. The National Strategy for Sexual Health and HIV. Better Prevention, Better Service, Better Sexual Health. London, UK: Department of Health, 2001.

3 Fenton KA. Screening men for Chlamydia trachomatis infection: have we explored the possibilities? Commun Dis Public Health 2000; 3: 86-89.

4 Hart G, Duncan B, Fenton KA. Chlamydia screening and sexual health. Sex Transm Infect 2002; 78: 396-397.

5 Rogstad IE. Men's sexual health: a neglected population. Sex Marital Ther 1996; 11: 211-214.

6 Lorimer K, Reid ME, Hart G. Willingness of young men and women to be tested for Chlamydia trachomatis in three nonmedical settings, in Glasgow, UK. J Family Plann Reprod Health Care 2009; 35: 21-26.

7 De Viggiani N. Unhealthy prisons: exploring structural determinants of prison health. Sociol Health IIIn 2007; 29: 115-135.

8 Stewart EC. The sexual health and behaviour of male prisoners: the need for research. Howard Law J 2007; 46: 43-59.

9 David N, Tang A. Sexually transmitted infections in a young offenders institution in the UK. Int J STD AIDS 2003; 14: 511-513.

10 Hollis V, Cross I. Prison Population Brief: England and Wales, London, UK: Home Office, Research Development and Statistics Directorate, 2003.

11 National Chlamydia Steering Group. New Frontiers: Annual Report of the National Chlamydia Screening Programme in England 2005/2006. London, UK: Health Protection Agency, 2006.

12 Centers for Disease Control and Prevention. Sexually Transmitted Disease Surveillance 2007. Atlanta, GA: US Department of Health and Human Services, 2009.

13 Satterwhite CL, Joesoef MR, Datta SD, Weinstock $H$. Estimates of Chlamydia trachomatis infections among men: United States. Sex Transm Dis 2008; 35(11 Suppl.): S3-S7.

14 Buston K. Behind and Beyond the Prison Bars: Young Offenders Talk about Sex and Relationships (Occasional Paper No. 18). Glasgow, UK: MRC Social and Public Health Sciences Unit, 2008. http://www.sphsu.mrc.ac.uk/files/File/library/ occasional/OP018.pdf [Accessed 18 December 2008]

15 Silverman D. Doing Qualitative Research. London, UK: Sage, 2005.

16 Ritchie J, Spencer L. Qualitative data analysis for applied policy research. In: Bryman A, Burgess RG (eds), Analyzing Qualitative Data. London, UKK: Routledge, 1994.

17 Scottish Executive. Prison Statistics Scotland 2007/08. Edinburgh, UK: Scottish Executive, 2008.

18 General Register Office for Scotland. Mid-2007 Population Estimates Scotland: Population Estimates by Sex, Age and Administrative Area. Edinburgh, UK: National Statistics, 2008. 
19 Wight D, West $P$. Poor recall, misunderstandings and embarrassment: interpreting discrepancies in young men's reported heterosexual behaviour. Cult Health Sex 1999; 1: 55-78.

20 Cornwell, J. Hard Earned Lives: Accounts of Health and IIIness from East London. London, UK: Tavistock, 1984.

21 West, P. The status and validity of accounts obtained at interview: a contrast between two studies of families with a disabled child. Soc Sci Med 1990; 30: 1229-1239.

22 Kernaghan K, Carrick-Anderson K, Clery H, McKay L, Scott G. Chlamydia Testing: Any Time, Any Place, Any Where, Edinburgh, UK: Healthy Respect, 2005.
23 Pimenta J, Catchpole M, Rogers P, Hopwood J, Randall S, Mallinson $\mathrm{H}$, et al. Opportunistic screening for genital chlamydial infection 1: Acceptability of urine testing in primary and secondary healthcare settings. Sex Transm Infect 2003; 79: 16-21.

24 Lorimer K. Non-medical approaches to screening young men and women for Chlamydia trachomatis. PhD thesis, University of Glasgow, Glasgow, UK, 2006.

25 Williamson LM, Scott G, Carrick-Anderson K, Kernaghan K, Hart GJ. Chlamydia trachomatis testing among 13-25-yearolds in non-genitourinary medicine settings. J Fam Plann Reprod Health Care 2007; 33: 177-182. 